\title{
The Hydrogen Bond. A Hundred Years and Counting
}

\section{Steve Scheiner}

\author{
Department of Chemistry and Biochemistry, Utah State University Logan, Utah 84322-0300, United \\ States
}

*Correspondence to: steve.scheiner@usu.edu

\begin{abstract}
Since its original inception, a great deal has been learned about the nature, properties, and applications of the H-bond. This review summarizes some of the unexpected paths that inquiry into this phenomenon has taken researchers. The transfer of the bridging proton from one molecule to another can occur not only in the ground electronic state, but in various excited states as well. Study of the latter process has developed insights into the relationships between the nature of the state, the strength of the H-bond, and the height of the transfer barrier. The enormous broadening of the range of atoms that can act as both proton donor and acceptor has led to the concept of the $\mathrm{CH} \cdots \mathrm{O} \mathrm{HB}$, whose properties are of immense importance in biomolecular structure and function. The idea that the central bridging proton can be replaced by any of various electronegative atoms has fostered the rapidly growing exploration of related noncovalent bonds that include halogen, chalcogen, pnicogen, and tetrel bonds.
\end{abstract}

Keywords: halogen bond; chalcogen bond; pnicogen bond; tetrel bond; excited state proton transfer; $\mathrm{CH} \cdots \mathrm{O}$ H-bond 


\section{INTRODUCTION}

Over the course of its century of study following its earliest conceptual formulation ${ }^{1-2}$, the hydrogen bond (HB) has surrendered many of the mysteries of its source of stability and its myriad occurrences. Indeed, one might be hard pressed to think of chemical or biological systems which are completely free of the effects of HBs. Proteins, carbohydrates, and nucleic acids alike owe much of their structure to this phenomenon. The many catalytic functions of enzymes are heavily dependent upon HBs between amino acid residues and substrates. In fact, water would not even exist as a liquid at room and biological temperatures were it not for H-bonding. And of course, one would not be able to understand the many chemical and biological processes that take place in aqueous environment without a thorough treatment of the HBs that occur in each such system.

The HB owes a large segment of its stability to simple Coulombic forces. The normal polarity of a A-H bond, wherein $\mathrm{A}$ is an electronegative atom like $\mathrm{O}$ or $\mathrm{N}$, places a partial positive charge on the proton. The latter can thus attract the partial negative charge of an approaching nucleophile D. Another important factor resides in the perturbation of the electronic structure of the two species as they approach one another. These alterations are typically referred to as induction, amongst other labels. At least conceptually, the perturbations can be categorized as internal and external. That is, charge shifts within a given molecule can result in polarization energy, while charge transfer refers to any electron density that crosses an imaginary border that separates the two entities. For example, it is common to speak of $n \rightarrow \sigma^{*}$ transfer by which some density is shifted from the nonbonding, i.e. lone pair, orbital of the nucleophile into the $\sigma^{*}(\mathrm{~A}-\mathrm{H})$ antibonding orbital of the proton donor. This accumulation of density in an antibonding orbital has been taken as the source of the weakening of the A-H covalent bond, and the resulting red shift of its stretching frequency, itself a hallmark of $\mathrm{H}-$ bonding. The latter density shifts, both internal and external, are sometimes referred to as "covalent" contributions, although this particular sobriquet can be rather vague. To all of the preceding terms, a last attractive contribution arises in connection with London dispersion, a factor which is common to all molecular interactions, HBs being no exception. Of course, if all components of the interaction were attractive, an AH $\cdots$ B HB would collapse into a single molecule. Such a collapse is prevented by Pauli exchange forces, similar in nature to what are colloquially referred to as steric repulsion.

While the earliest concept of a $\mathrm{AH} \cdots \mathrm{D}$ HB was predicated on only the very electronegative $\mathrm{O}, \mathrm{N}$, and $\mathrm{F}$ atoms as $\mathrm{A}$ or $\mathrm{D}$ participants, the list of atoms that can serve in this capacity has greatly expanded over the years. All of the halogens have been shown ${ }^{3-7}$ capable, as have numerous chalcogen ${ }^{8-17}$ and pnicogen atoms ${ }^{18-20}$. The list has been extended to metal atoms as well ${ }^{21-28}$, both 
as proton donors and acceptors. In terms of nucleophilic proton acceptors, the original idea of lone pairs has also been extended, now to include $\pi$-systems of units such as alkenes or aromatics ${ }^{29-35}$. Even the $\sigma$-bonds of molecules such as $\mathrm{H}_{2}$ can serve ${ }^{36-40}$ this function. Yet another new concept is connected ${ }^{41}$ with the ability of a through-space $\alpha$-interaction between two lone pairs on different atoms to strengthen the $\mathrm{H}$-bond with a $\mathrm{CH}$ donor. In fact, the definition of the $\mathrm{HB}$ has expanded so much over the past few decades that a IUPAC group has established a new set of guidelines ${ }^{42}$ that are quite general.

Since there are already available scores of works on HBs, including a number of extensive monographs ${ }^{43-50}$ that concentrate on the central issues of this phenomenon, this review focuses on some of the currently developing frontiers of the concept. As proton transfers within HBs have received a good deal of attention, and much has been written about them, the first topic considered here is the extension of this idea to proton transfers within excited states of HBs. Although of some importance in a number of areas, such as laser development, far less is known about this process in any of its excited states than its ground state analogue. A second frontier discussed here is the ability of the $\mathrm{C}$ atom to participate as a $\mathrm{HB}$ proton donor. Despite the low electronegativity of $\mathrm{C}$, that generally precludes the normal ${ }^{-} \mathrm{A}-\mathrm{H}^{+}$polarization, there is growing evidence of $\mathrm{CH} \cdots \mathrm{O} \mathrm{HBs}$, and their importance in numerous phenomena. Lastly, discussion turns to a rapidly evolving field of close cousins of HBs, which in an apparent paradox, do not involve a $\mathrm{H}$ atom at all.

\section{EXCITED STATE PROTON TRANSFER}

Perhaps the first observation of a proton transfer in an excited state dates to 1956 and refers to the intramolecular HB within a methyl salicylate molecule ${ }^{51}$. The first documented case of excited state concerted double proton transfer occurred in the 7-azaindole dimer ${ }^{52}$. Dual fluorescence in 3hydroxyflavone was explained on the basis of this process in $1979^{53}$, and this process was placed in the context of a photoinduced proton transfer laser as the process required only $8 \mathrm{ps}{ }^{54}$. In addition to lasers, the excited state proton transfer process has implications for data storage device and optical switching ${ }^{55-57}$, Raman filters and scintillation counters ${ }^{58}$, triplet quenchers ${ }^{59-60}$, and polymer photostabilizers ${ }^{61-62}$.

The poster boy for examining intramolecular proton transfer, partly due to its simplicity, is the malonaldehyde molecule which contains an internal $\mathrm{OH}^{\cdots} \mathrm{O} \mathrm{HB}$ within a conjugated ring structure, as pictured in Fig 1. The bridging proton can transfer across to the other $\mathrm{O}$ atom which results in a symmetrically equivalent system. The transition state (TS) for this transfer is a symmetric 
configuration with the proton equidistant between the two $\mathrm{O}$ atoms. An early study of this transfer ${ }^{63}$ comprised both the ground state $S_{0}$ and the first excited $\pi \rightarrow \pi^{*}$ triplet state, $T_{1}$. The excitation into this state required on the order of $95 \mathrm{kcal} / \mathrm{mol}$, and had several effects. It reduced the acidity of the $\mathrm{OH}$ group, as well as the basicity of the other $\mathrm{O}$, and weakened the internal HB. Another result of the excitation is the addition of antibonding character to the $\mathrm{C}=\mathrm{O}$ bond, which causes it to elongate. The bottom line is a higher $\mathrm{pT}$ barrier in $\mathrm{T}_{1}$ than in $\mathrm{S}_{\mathrm{o}}, 13.6 \mathrm{vs} 3.6 \mathrm{kcal} / \mathrm{mol}$. This concept was expanded ${ }^{64}$ to include other excited states as well. The ${ }^{3} \pi \pi^{*},{ }^{3} \mathrm{n} \pi^{*},{ }^{1} \pi \pi^{*}$, and ${ }^{1} \mathrm{n} \pi^{*}$ states all displayed a rise in pT barrier vs the ground state, and indeed, a number showed barrierless pT. The height of the barrier was inversely correlated with the strength of the internal HB.

Research has progressed on malonaldehyde and its related systems over the ensuing years and continues unabated ${ }^{65-67}$. The excited state proton transfer process is apparently important even in terms of the ground state. A very recent examination of the proton transfer ${ }^{68}$ implicated the two lowest excited singlet states in the properties of the ground state transfer via conical intersections. Measurements and later calculations place the height of the ground state proton transfer barrier at 5 $\mathrm{kcal} / \mathrm{mol}$, while the transfer in the ${ }^{1} \pi \pi^{*}$ state is barrierless, and a high barrier occurs in the ${ }^{1} \mathrm{n} \pi^{*}$ state ${ }^{68-70}$, similar to the results obtained years earlier ${ }^{64}$.

A number of modifications to the basic malonaldehyde conjugated ring structure were examined next in the context of glyoxalmonohydrazine. Replacement of the OCCCO ring by OCCNN raised the possibility ${ }^{71}$ of different energies for the enol and keto structures, i.e. proton on $\mathrm{O}$ or $\mathrm{N}$, as indicated in Fig 2. The ground state pT potential contains two minima, $\mathbf{O}$ and $\mathbf{N}$, with the latter lower by some $9 \mathrm{kcal} / \mathrm{mol}$. The pT from $\mathrm{N}$ to $\mathrm{O}$ most pass over an energy barrier of only $2 \mathrm{kcal} / \mathrm{mol}$. The situation is generally similar in the ${ }^{1} \pi \pi^{*}$ and ${ }^{3} \pi \pi^{*}$. The situation is reversed in the singlet and triplet $\mathrm{n} \pi^{*}$ states, where $\mathbf{O}$ is preferred to $\mathbf{N}$ by $1 \mathrm{kcal} / \mathrm{mol}$ in ${ }^{1} \pi \pi^{*}$ and by 14 in the triplet. Unlike the malonaldehyde analogue, most of the excited states of glyoxalmonohydrazine favor a nonplanar geometry. The specific distortion mode is different for each state, as is the force toward nonplanarity. Permitting full distortion has a profound influence upon the energetics of pT, switching the relative stability of $\mathbf{N}$ and $\mathbf{0}$ in both excited singlets, as compared to the transfer in the planar case. The situation was modified by replacing the $\mathrm{H}$ on the $\mathrm{N}$ by a $=\mathrm{CH}_{2}$ group ${ }^{72}$. This perturbation leads to an interesting situation wherein the keto tautomer does not represent a minimum in the ground electronic state, but the reverse is true for either the first excited singlet or triplet, where it is only the keto minimum that is present. This system thus represents a pT that is forced by the excitation. 
The entire system was remade ${ }^{73}$ into a symmetric system, wherein both $\mathrm{O}$ atoms of malonaldehyde are replaced by NH groups, as displayed in Fig 3. As in the unsubstituted malonaldehyde, a correlation is noted in that the stronger the $\mathrm{HB}$, the lower the barrier to proton transfer. Nonplanar distortions are different for each excited state, but because the distortions have similar energetic consequences for the equilibrium and transition state structures, the pT barrier of the ${ }^{1} \mathrm{n} \pi *$ state is little affected by permitting such deformations. As for malonaldehyde molecule, the transfer barriers in either case obey the order ${ }^{1} \pi \pi^{*}<S_{O}<{ }^{3} \pi \pi^{*}<{ }^{n} n *<{ }^{3} n \pi^{*}$. The barriers are uniformly higher for the intemitrogen transfers than for the $\mathrm{OH} \cdot{ }^{*} \mathrm{O}$ interaction in malonaldehyde, which is attributed to the longer HBs. For any given $\mathrm{H} \beta$, the interoxygen transfer has a slightly higher barrier than does $\mathrm{NH}-\mathrm{N}$ by $2-3 \mathrm{kcal} / \mathrm{mol}$.

The effects of the 5-membered ring size of malonaldehyde change to both 4 and 6, coupled with addition of a negative charge, while holding the $\mathrm{HB}$ atoms to $\mathrm{O}$, was examined ${ }^{74}$ in a series of systems pictured in Fig 4. The pT barriers correlate strongly with various geometric and energetic markers of the strength of the HB. The H-B is weakened by $n \rightarrow \pi^{*}$ excitation, particularly for the neutral molecule, resulting in a higher barrier. In the case of the two anions, excitation to ${ }^{3} \pi \pi^{*}$ strengthens the HB, while the result is more ambiguous for the ${ }^{1} \pi \pi^{*}$ state. This trend is reversed in malonaldehyde where the singlet is strengthened by the excitation and the triplet weakened. Some of these patterns were traced directly to the nature of the pertinent orbitals and the density shifts arising from the excitation.

The malonaldyde theme was added to a phenyl ring in such a way as to perturb the intrinsic symmetry of the pT process, which was augmented by inclusion of a methyl group in ohydroxyacetophenone ${ }^{75}$, as illustrated in Fig 5. The correlated pT potentials for the ground and first excited singlet states each contain a single minimum, but they differ in placement of the proton. Hence the $\mathrm{S}_{0} \rightarrow \mathrm{S}_{1}$ excitation yields a spontaneous $\mathrm{pT}$, from the hydroxyl $\mathrm{O}$ to the carbonyl $\mathrm{O}$. Attachment to a phenyl ring was also examined ${ }^{76}$ in the closely related o-hydroxybezaldehyde (oHBA), wherein the methyl group of hydroxyacetophenone is removed. In most respects, the addition of the aromatic system exerts little influence upon the properties of malonaldehyde. With the exception of the ${ }^{1} \pi \pi^{*}$ state, electronic excitation weakens the HB and simultaneously raises the pT barrier in either system. Unlike the symmetric transfer potential in malonaldehyde, the enol and keto tautomers of $o \mathrm{HBA}$ are chemically distinct. $\pi \pi^{*}$ excitation reverses the preference for the enol tautomer in the ground state. This reversal is connected with the changing degree of aromaticity in the phenyl ring of $o$ HBA. The asymmetric transfer potential in $o$ HBA leads to forward and reverse 
barriers of different magnitude. When this factor is accounted for by an averaging procedure, the transfer barriers in $o \mathrm{HBA}$ are similar to those of the corresponding states of malonaldehyde.

Another variation of the theme shrunk the HB segment down to a 4-membered OCCO ring, which is then attached to a 7-membered hydrocarbon ring as in tropolone, illustrated in Fig 6. The

pT process in the $\mathrm{S}_{1}$ state ${ }^{77}$ is characterized by a low barrier, such that only one doublet of the $\mathrm{OH}$ stretching frequency lies below the peak of the pT barrier. A careful analysis of the tunneling splitting revealed that bending vibrations play only a minor role in the $\mathrm{pT}$ process so that a 2dimensional stretching model, involving only $\mathrm{O} \cdots \mathrm{O}$ and $\mathrm{O}-\mathrm{H}$ stretches ought to be adequate.

Attachment to a phenyl ring was also considered in the context of salicylaldimine, which contains the symmetric OCCCN ring, and in particular how the pT potential is affected by F substitution ${ }^{78}$ as indicated in Fig 7. Many of the effects are inductive; the electronegative $\mathrm{F}$ makes the proximate $\mathrm{N}$ or $\mathrm{O}$ atom a stronger acid or weaker base and thereby modulates the preferred position of the proton. The agnitude of the perturbation diminishes as the site of substitution is further removed from the $\mathrm{HB}$. This principle also controls the manner in which $\mathrm{F}$ affects the geometry and strength of the intramolecular HB in both the enol and keto tautomers. Whereas these notions apply fairly consistently to the ground state and excited $\pi \pi^{*}$ singlet and triplet, a number of anomalous patterns emerged in the ${ }^{1} n \pi^{*}$ state. In general, the effects of fluorosubstitution are smaller in magnitude than the changes that occur in the pT properties as a result of electronic excitation.

While the results described above concerned intramolecular pT through an internal $\mathrm{HB}$, it is also of interest to consider intermolecular processes. An example is the transfer of a proton from phenol to ammonia ${ }^{79}$ which would morph the system from a neutral $\mathrm{PhOH}^{\cdots} \mathrm{NH}_{3}$ pair to a $\mathrm{PhO}^{-\cdot .}{ }^{+} \mathrm{HNH}_{3}$ ion pair. While such a transfer is highly disfavored in the ground state, the situation changes dramatically in the first excited singlet state where the pT potential develops a second minimum, with the two configurations roughly equal in energy.

More details about these results, and the specific methods applied can be found in the original papers as well as a summarizing Feature Article ${ }^{80}$. Work has certainly not ceased in this field, which continues apace ${ }^{81-83}$ from both computational and experimental perspectives.

\section{$\mathrm{CH} \cdots \mathrm{O}$ H-BONDS}

Another frontier in the definition and properties of $\mathrm{H}$-bonding lies on the weak end of the spectrum. The $\mathrm{C}-\mathrm{H}$ group is so pervasive in chemistry and biochemistry, that its ability to participate in a $\mathrm{HB}$ is of utmost importance. While a simple alkane does not provide a sufficiently polar $\mathrm{CH}$ 
group to act in this fashion, it is well documented that a HB is formed if the $\mathrm{C}$ changes its hybridization ${ }^{84-85}$ from $\mathrm{sp}^{3}$ to $\mathrm{sp}$, as in $\mathrm{HC} \equiv \mathrm{CH}$ or $\mathrm{N} \equiv \mathrm{CH}$. Another means to amplify the $\mathrm{CH}$ polarity is the placement of electron-withdrawing substituents on the $\mathrm{C}$, as would naturally occur in a protein where each $\mathrm{C}^{\alpha} \mathrm{H}$ is flanked by a pair of peptide groups. As work proceeded on $\mathrm{CH} \cdots \mathrm{O}$ HBs, it was soon apparent that some of them have an unusual quirk. Instead of shifting the A-H stretching frequency to the red as had been taken as a necessary condition of a $\mathrm{AH} \cdot{ }^{\circ} \mathrm{D} \mathrm{HB}$, a certain subset of $\mathrm{CH} \cdot{ }^{*} \mathrm{O}$ interactions shifted the $\mathrm{C}-\mathrm{H}$ stretch to the blue ${ }^{86-92}$. While there were some initial complaints that such a shift in the wrong direction ought to disqualify this interaction as being a true HB, it fulfilled all other typical criteria. This anomaly was soon determined to result from the fact that the direction of shift arises from a delicate balance between forces, some tending to shift to the red, and others to the blue ${ }^{93-101}$. While the former tend to win out in most HBs, the subtle balance simply shifts in the opposite direction for some $\mathrm{CH} \cdots \mathrm{O}$ HBs ${ }^{102-106}$.

Within the realm of proteins, the most common $\mathrm{CH}$ group capable to participate in such a bond is the $\mathrm{C}^{\alpha} \mathrm{H}$ group which is surrounded by a pair of electron-withdrawing peptide groups. Calculations have demonstrated the strength of these bonds ${ }^{107}$ as just less than that of a standard $\mathrm{NH} \cdot{ }^{\cdot} \mathrm{O}$ interaction. With respect to sidechains containing an aromatic group, e.g. Tyr or Im, the $\mathrm{CH}$ of the aromatic ring was also a viable proton donor 108 .

It had been part of conventional wisdom that it is the $\mathrm{NH}^{\cdot} \mathrm{O}$ HBs between strands that hold the $\beta$ sheet together. But study of the atomic positions of a $\beta$-sheet in Fig 8 shows that $\mathrm{CH}$ groups are also in position to donate a proton to the peptide $\mathrm{O}$ of the neighboring strand. Quantum calculations ${ }^{109}$ showed that these putative interstrand $\mathrm{CH}^{*} \mathrm{O}$ HBs are competitive in strength with $\mathrm{NH} \cdot \cdot \mathrm{O}$, and serve as an integral component in the stability of the $\beta$-sheet, a finding that has since been confirmed by others ${ }^{110-115}$.

Despite a longstanding notion that the strength of a HB between two given groups depends only upon their relative geometry, i.e. HB length and angles, calculations showed this to only be part of the story. Even when a pair of peptide groups is locked into a given configuration ${ }^{116}$, the interaction energy is highly sensitive to the overall structure of the polypeptide chain on which they reside. In particular, extended conformations of a polypeptide are capable of only weak $\mathrm{NH}^{*} \mathrm{O}$ HBs, and the interstrand $\mathrm{NH} \cdots \mathrm{O}$ H-bonds in $\beta$-sheets are weaker than those found in other conformations, such as helices, ribbons, and $\beta$-bends, even if the specific HB geometries are similar. In a related vein, the $\mathrm{CH}^{*} \mathrm{O} \mathrm{HB}$ is even stronger than $\mathrm{NH}^{*} \mathrm{O}$ within the context of a simple dipeptide ${ }^{106}$ when in a $\mathrm{C}_{5}$ geometry, a small model somewhat similar to the $\beta$-sheet. These trends are not restricted only to in 
vacuo settings, but retain their integrity within the context of a dielectric continuum model of a protein interior $^{117}$.

The importance of the $\mathrm{CH} \cdot \mathrm{O} \mathrm{HB}$ is not limited to structural issues, but also plays a role in various enzymatic mechanisms. These ideas were tested within the context of the serine proteinase family of enzymes ${ }^{118}$. Earlier workers had suggested what they called a "ring-flip" hypothesis involving a $180^{\circ}$ rotation of a key His residue as a vital step in the catalysis. This mechanism relied on the presence of a $\mathrm{CH} \cdot{ }^{*} \mathrm{O} \mathrm{HB}$ in order to stabilize one of the intermediates in the formation of the tetrahedral intermediate. The calculations were generally supportive of this idea but raised some important discrepancies that required resolution before its acceptance. This sort of HB has implications in other enzymatic mechanisms as well ${ }^{119}$. There are also contributions of this weak $\mathrm{HB}$ as a determining factor ${ }^{120-122}$ in the conformation of certain organic systems. Needless to say, even normally weak HBs can be strengthened by the acquisition of charge on either the proton donor or acceptor group ${ }^{123-125}$.

As experimentalists continue to examine systems for the presence of $\mathrm{CH}^{\cdot} \mathrm{O} \mathrm{HBs}$, they require certain trademark or fingerprint characteristics for which to search. In addition to geometric aspects which are already fairly well understood, it is common to apply spectroscopic methods to these biological systems. Quantum calculations have provided some such characteristics for which to search ${ }^{126-128}$. It was noted earlier that $\mathrm{CH}$ stretching frequencies can shift in either direction; nonetheless a blue shift would be a valuable indicator as it would not occur in the absence of such a bond. A downfield shift of the bridging proton's NMR signal would reinforce this supposition. With respect to the proton acceptor, a large upfield shift of the $\mathrm{O}$ chemical shift, by as much as $16 \mathrm{ppm}$, can serve as another indicator.

\section{COUSINS OF THE H-BOND}

Another HB frontier that has been approached is its definition as an interaction involving a bridging proton. Suppose this $\mathrm{H}$ were to be replaced by a different atom, but the various properties were to remain largely intact. Early work had suggested such a phenomenon, wherein $\mathrm{H}$ could be replaced by any of several halogen $(X)$ atoms ${ }^{129-131}$. The ability of the $X$ to serve in this capacity rests on the highly anisotropic charge distribution which surrounds it. While its electronegativity imparts to it an overall negative partial charge, there is a reduced density along the extension of the R-X bond, which has been termed a "polar flattening", which in turn causes a region of positive 
electrostatic potential in this region, commonly referred to as a $\sigma$-hole ${ }^{132-136}$. It is this localized positive region which can attract a nucleophile, in much the same way as does the $\mathrm{H}$ in a $\mathrm{AH} \cdot \mathrm{D} \mathrm{HB}$.

This idea of a halogen bond (XB) is not restricted only to halogen atoms, but is common also to chalcogen, pnicogen, and even tetrel atoms, in their eponymously named bonds. There are certain fine point differences amongst these bonds. For example, while a univalent $\mathrm{X}$ atom displays a single $\sigma$-hole lying along the extension of the $\mathrm{R}-\mathrm{X}$ bond, a divalent $\mathrm{Y}$ chalcogen atom will typically contain two such $\sigma$-holes, each lying along an extension of the two R-Y bonds. These holes will not be able to lie directly opposite the bond, since the high electron density of the two Y lone pairs will tend to push the holes away from them. This distinction is illustrated in the comparison of FCl with HFS in Figs $9 \mathrm{a}$ and $9 \mathrm{~b}$, respectively. In each case, the blue oval represents the $\sigma^{*}$ antibonding orbital, $\mathrm{FCl}$ in $\mathrm{a}$ and FS in $\mathrm{b}$, along which the reduced electron density would tend toward a $\sigma$-hole. The $\mathrm{Cl}$ atom of $\mathrm{FCl}$ contains three lone pairs, represented by red ovals, whose density would push the positive potential, i.e. the $\sigma$-hole, away from themselves. Due to their symmetric disposition, the blue region of the potential lies directly along the $\mathrm{F}-\mathrm{Cl}$ axis and the $\sigma^{*}$ orbital direction. On the other hand, there are only two lone pairs on the $\mathrm{S}$ atom in Fig 9b, which together push the $\sigma$-hole down away from them. A nucleophile would thus tend toward this blue region $\sigma$-hole, and a nonlinear FS $\cdots$ Nuc alignment. A similar nonlinear arrangement between the F-P bond extension and the $\sigma$-hole would be expected for a pnicogen bond (ZB), in Fig 9c, due to a single lone pair. The absence of any lone pairs on the Si atom in Fig 9d would allow the blue positive potential $\sigma$-hole to align perfectly with the $\sigma^{*}(\mathrm{~F}-\mathrm{Si})$ antibonding orbital, resulting in a linear tetrel bond (TB). It must be noted that since the high electron density of lone pairs mitigate the positively charged $\sigma$-hole, the progressive decrease of lone pair number in the sequence halogen $>$ chalcogen $>$ pnicogen $>$ tetrel would tend to enhance the $\sigma$-hole intensity in the same order.

After an initial study that demonstrated that a $\mathrm{P} \cdots \mathrm{N}$ interaction is energetically preferred to a $\mathrm{PH}^{\cdots} \mathrm{N} \mathrm{HB}^{137}$, more detailed study ${ }^{138}$ showed this to be a characteristic of pnicogen bonds in general. Part of the interaction arises from the donation of charge from the $\mathrm{N}$ lone pair into the $\sigma^{*}(\mathrm{PH})$ antibonding orbital. This transfer is identical to that in a $\mathrm{PH} \cdot{ }^{*} \mathrm{~B} \mathrm{HB}$, except that it is the $\mathrm{P}$ end of this orbital which points toward the $\mathrm{N}$, rather than the $\mathrm{H}$-end. The strength of such a ZB is heightened when the $\mathrm{H}$ is replaced by an electron-withdrawing agent such as $\mathrm{F}^{139}$. Fig 10 shows how the interaction energy $\Delta \mathrm{E}$ rises as the substituent's electron-withdrawing power increases from $\mathrm{CH}_{3}$ and $\mathrm{H}$ up to $\mathrm{F}$ and $\mathrm{NO}_{2}$ for the $\mathrm{XH}_{2} \mathrm{P} \cdots \mathrm{NH}_{3}$ series ${ }^{140}$. Along with this rise in binding is a 
concomitant amount of charge transferred from the base to the Lewis acid, as measured either by $\mathrm{NBO}$ values of $\mathrm{E}(2)$ or the total charge on the entire subunit $\Delta \mathrm{q}$.

In fact, this substitution is even capable of making first-row $\mathrm{N}$ capable of accepting charge in a $\mathrm{N} \cdot \mathrm{N}$ pnicogen bond ${ }^{141}$ despite the reluctance of first-row atoms to engage in such bonds. With respect to the electronegativity and polarizability of the pnicogen atom, larger atoms yield stronger ZBs ${ }^{140,142-143144}$ in the order $\mathrm{P}<\mathrm{As}<\mathrm{Sb}$. This trend has no parallel to HBs as it is always the proton that acts as bridge.

As one might anticipate, since halogen and pnicogen atoms can replace the proton in $\mathrm{HBs}$, the same idea can be extended to chalcogen (S, Se, etc) atoms as well. Work by our group ${ }^{145-149}$ as well as numerous others ${ }^{150-156}$ elaborated on these ideas. Indeed, there is currently a IUPAC group tasked with adopting a working definition of a chalcogen bond, with others to follow later for the other sorts. The extension to tetrel atoms (the Si family) occurred soon thereafter, showing many of the same controlling factors that are present for X, Y, and Z atoms ${ }^{157-160}$. The normally tetravalent tetrel atoms introduced a new factor which had been less prominent in the other sorts of bonds. In order for a base to approach the central tetrel atom along a face of the tetrahedron, the three proximate substituents must "peel back" away from this base, changing the originally tetrahedral structure into something akin to a trigonal bipyramid. There is thus a good deal of deformation energy that must be surmounted ${ }^{161-163}$ if this tetrel bond is to form. This deformation energy makes the tetrel bond formation less exothermic than it would otherwise be, and can even control the particular site at which the base can attack.

The idea of tetrel bonds brought up an interesting issue. It had typically been considered that a nucleophile lying along the $\mathrm{R}-\mathrm{C}$ extension of a $\mathrm{R}-\mathrm{CH}_{3}$ group constituted a trifurcated $\mathrm{HB}$, i.e. interaction with three $\mathrm{H}$ atoms. And there are certainly many such geometrical dispositions of this sort, in both chemical and biological systems ${ }^{164}$. But how can one distinguish this idea of a trifurcated HB from the newer concept of a R-C $\cdots$ D tetrel bond? Indeed there are spectroscopic markers that are different for the two sorts of interactions ${ }^{165-166}$, and it is hoped that the future will witness attempts to distinguish these two types of interactions.

As work has progressed in this area, it has become recognized that the positive regions are not limited only to $\sigma$-holes lying along the extension of a particular covalent bond. There are $\pi$-holes as well, wherein the positive potential sits above the plane of a molecule, as in $\mathrm{H}_{2} \mathrm{SiO}$ for example, in the vicinity of the electronic $\pi$-cloud. This broadening of the idea has been probed extensively and shown that while the $\pi$-hole interactions are usually weaker than their $\sigma$ parallels, this trend is 
sometimes reversed $^{158,167-169}$, especially when the $\pi$-hole lies above a triel atom such as $\mathrm{B}$ or $\mathrm{Al}{ }^{170-}$

173. Of course, such $\pi$-hole interactions do not have a H-bonding parallel.

These relatives of the HB are hardly exotic academic novelties, but have a wide range of applications, such as serving as synthons in self-assembling networks ${ }^{174}$, biological catalysis ${ }^{175}$, oxidative addition ${ }^{176}$, self-assembled monolayers ${ }^{177}, \mathrm{~S}_{\mathrm{N}} 2$ reaction catalysis ${ }^{178}$, design of functional mesomorphic materials ${ }^{179}$, and even directed construction of supramolecular quadruple and double

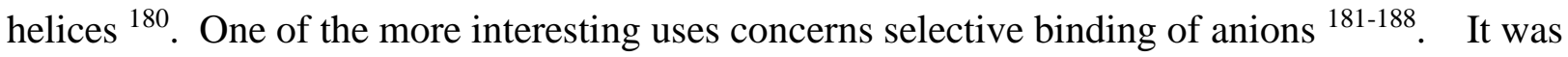
realized that the replacement of the $\mathrm{H}$ atom of certain multidentate anion receptors with a halogen atom allowed them to engage in halogen bonds with an anion, which in turn strengthened the interaction, and enhanced the selectivity for certain anions over others.

Calculations were applied to this idea, and were able to suggest certain options that ought to enhance these abilities. Optimal choices of particular halogen atoms were proposed, along with identification of chemical groups to which they ought to be bonded, spacer groups between the halogen bonding groups, and overall charge ${ }^{189-191}$. Subsequent work broadened this idea beyond simply halogen bonds, but considered their chalcogen, pnicogen, and tetrel counterparts ${ }^{192-195}$. It was concluded that tetrel bonds offered a particularly tempting choice for their interactions with a halide, furnishing both very strong interactions, and a marked preference for $\mathrm{F}^{-}$over other halides.

\section{PERSPECTIVE}

It would seem then that even after a full century of study, which has provided a wealth of information and insights about the H-bond, we are nowhere near the end of learning its secrets. Its fundamental nature is a template for a much broader set of interactions. Far from the initial thoughts that the $\mathrm{A}$ and $\mathrm{B}$ atoms in the $\mathrm{AH} \cdots \mathrm{B}$ interaction are limited to $\mathrm{O}, \mathrm{N}$, and $\mathrm{F}$, the set of participating atoms has broadened so widely over the years, such that an atom that cannot serve in this capacity would be the exception, not the rule. In particular, the entry of the $\mathrm{CH}$ group into the club of protondonating members, has opened wide new vistas concerning the structure and function of large molecules including proteins and nucleic acids, vistas that are only recently beginning to be explored. The possibility of proton transfer within a given HB has enormous implications as well, not only in the ground electronic state but also in various excited states which open new sets of practical applications. And the further broadening of the original concept of a proton-bridging HB to systems where this central proton is replaced by any of a large number of electronegative atoms has 
introduced an entire new area that encompasses halogen, chalcogen, pnicogen, and tetrel bonds, again an area whose impact is only beginning to emerge.

Given all that has transpired in the last century, it would be foolish to presume that we have reached the final border of what the $\mathrm{H}$-bond has to teach us. One can only hope that the next century of inquiry will be as fruitful as the first. 


\section{REFERENCES}

1. W. M. Latimer and W. H. Rodebush, Polarity and ionization from the standpoint of the Lewis theory of valence, J. Am. Chem. Soc. 42, 1419-1433 (1920)

2. L. Pauling. The nature of the chemical bond. Cornell University Press: Ithaca, NY, 1940; p 450.

3. D. O'Reilly, R. S. Stein, M. B. Patrascu, S. K. Jana, J. Kurian, N. Moitessier and M. J. Damha, Exploring Atypical Fluorine-Hydrogen Bonds and Their Effects on Nucleoside Conformations, Chem. Eur. J. 24, 16432-16439 (2018)

4. S. R. Chaudhari, S. Mogurampelly and N. Suryaprakash, Engagement of $\mathrm{CF}_{3}$ group in N-H $\cdots \mathrm{F}-$ C hydrogen bond in the solution state: NMR spectroscopy and MD simulation studies, J. Phys. Chem. B 117, 1123-1129 (2013)

5. J. Nadas, S. Vukovic and B. P. Hay, Alkyl chlorides as hydrogen bond acceptors, Comput. Theor. Chem. 988, 75-80 (2012)

6. L.-L. Lai, C.-M. Yang, C.-C. Liu, K.-L. Cheng, Y.-S. Wen, C.-H. Hung, T.-T. Luo and M.-Y. Kuo, Direct evidence of a liquid-crystalline phase induced by intermolecular $\mathrm{CH} \cdots \mathrm{Cl}$ interactions on the basis of IR spectroscopy and theoretical simulations, Chem. Eur. J. 17, 111-116 (2011)

7. L. Brammer, E. A. Bruton and P. Sherwood, Understanding the Behavior of Halogens as Hydrogen Bond Acceptors, Cryst. Growth Des. 1, 277-290 (2001)

8. K. K. Mishra, S. K. Singh, S. Kumar, G. Singh, B. Sarkar, M. S. Madhusudhan and A. Das, Water-Mediated Selenium Hydrogen-Bonding in Proteins: PDB Analysis and Gas-Phase Spectroscopy of Model Complexes, J. Phys. Chem. A 123, 5995-6002 (2019)

9. D. K. Sahoo, S. Jena, J. Dutta, A. Rana and H. S. Biswal, Nature and Strength of M-H $\cdots S$ and $\mathrm{M}-\mathrm{H} \cdots \mathrm{Se}(\mathrm{M}=\mathrm{Mn}, \mathrm{Fe}$, \& Co) Hydrogen Bond, J. Phys. Chem. A 123, 2227-2236 (2019)

10. A. Das, P. K. Mandal, F. J. Lovas, C. Medcraft, N. R. Walker and E. Arunan, The $\mathrm{H}_{2} \mathrm{~S}$ Dimer is Hydrogen-Bonded: Direct Confirmation from Microwave Spectroscopy, Angew. Chem. Int. Ed. 57, 15199-15203 (2018)

11. S. Wategaonkar and A. Bhattacherjee, $\mathrm{N}-\mathrm{H} \cdots \mathrm{S}$ Interaction Continues To Be an Enigma: Experimental and Computational Investigations of Hydrogen-Bonded Complexes of Benzimidazole with Thioethers, J. Phys. Chem. A 122, 4313-4321 (2018)

12. V. R. Mundlapati, S. Gautam, D. K. Sahoo, A. Ghosh and H. S. Biswal, Thioamide, a Hydrogen Bond Acceptor in Proteins and Nucleic Acids, J. Phys. Chem. Lett. 8, 4573-4579 (2017)

13. K. K. Mishra, S. K. Singh, P. Ghosh, D. Ghosh and A. Das, The nature of selenium hydrogen bonding: gas phase spectroscopy and quantum chemistry calculations, Phys. Chem. Chem. Phys. 19, 24179-24187 (2017)

14. C. L. Andersen, C. S. Jensen, K. Mackeprang, L. Du, S. Jørgensen and H. G. Kjaergaard, Similar Strength of the NH $\cdots \mathrm{O}$ and $\mathrm{NH} \cdots \mathrm{S}$ Hydrogen Bonds in Binary Complexes, J. Phys. Chem. A 118, 11074-11082 (2014)

15. B. J. Mintz and J. M. Parks, Benchmark interaction energies for bologically relevant noncovalent complexes containing divalent sulfur, J. Phys. Chem. A 116, 1086-1092 (2012)

16. H. S. Biswal and S. Wategaonkar, $\mathrm{OH} \cdots \mathrm{X}(\mathrm{X}=\mathrm{O}, \mathrm{S})$ hydrogen bonding in thetrahydrofuran and tetrahydrothiophene, J. Chem. Phys. 135, 134306 (2011)

17. H. S. Biswal and S. Wategaonkar, Sulfur, not too far behind O, N, and C: SH $\cdots \pi$ hydrogen bond, J. Phys. Chem. A 113, 12774-12782 (2009)

18. K. H. Møller, A. S. Hansen and H. G. Kjaergaard, Gas Phase Detection of the NH-P Hydrogen Bond and Importance of Secondary Interactions, J. Phys. Chem. A 119, 10988-10998 (2015) 
19. R. B. Viana and A. B. F. da Silva, Interaction between $\mathrm{PH}_{3}$ and small water clusters: Understanding the electronic and spectroscopic properties, Comput. Theor. Chem. 1059, 35-44 (2015)

20. A. S. Hansen, L. Du and H. G. Kjaergaard, Positively Charged Phosphorus as a Hydrogen Bond Acceptor, J. Phys. Chem. Lett. 5, 4225-4231 (2014)

21. H. Schmidbaur, Proof of Concept for Hydrogen Bonding to Gold, Au $\cdots \mathrm{H}-\mathrm{X}$, Angew. Chem. Int. Ed. 58, 5806-5809 (2019)

22. P. Wang, H.-G. Xu, G.-J. Cao, W.-J. Zhang, X.-L. Xu and W.-J. Zheng, Nonconventional Hydrogen Bonds between Silver Anion and Nucleobases: Size-Selected Anion Photoelectron Spectroscopy and Density Functional Calculations, J. Phys. Chem. A 121, 8973-8981 (2017)

23. R. Sanchez-de-Armas and M. S. G. Ahlquist, On the nature of hydrogen bonds to platinum(II) - which interaction can predict their strength?, Phys. Chem. Chem. Phys. 17, 812-816 (2015)

24. H. Schmidbaur, H. G. Raubenheimer and L. Dobrzanska, The gold-hydrogen bond, Au-H, and the hydrogen bond to gold, AuH-X, Chem. Soc. Rev. 43, 345-380 (2014)

25. L. R. Falvello, The hydrogen bond, front and center, Angew. Chem., Int. Ed. Engl. 49, 1004510047 (2010)

26. S. Rizzato, J. Bergès, S. A. Mason, A. Albinati and J. Kozelka, Dispersion-driven hydrogen bonding: Predicted hydrogen bond between water and patinum(II) identified by neutron diffraction, Angew. Chem., Int. Ed. Engl. 49, 7440-7443 (2010)

27. E. S. Kryachko and F. Remacle, Three-gold clusters form nonconventional hydrogen bonds O$\mathrm{H} \cdots \mathrm{Au}$ and $\mathrm{N}-\mathrm{H} \cdots \mathrm{Au}$ with formamide and formic acid, Chem. Phys. Lett. 404, 142-149 (2005)

28. J. Kozelka. Agostic and Hydrogen-Bonding $\mathrm{X}-\mathrm{H} \cdot \cdots \mathrm{M}$ Interactions Involving a $\mathrm{d}^{8}$ Metal Center: Recent Advances Towards Their Understanding. In Noncovalent Forces, Scheiner, S., Ed. Springer: Dordrecht, 2015; Vol. 19, pp 129-158.

29. E. Ventura, S. A. D. Monte, W. Fragoso, C. F. Braga and R. C. M. U. Araújo, Effects of $\pi$ bond type, backbone size, and halogen on structural and spectroscopic properties of hydrogenbonded complexes of the $\mathrm{XH} \cdots \pi$ type between alkenes or alkynes and haloacids ( $\mathrm{HF}$ and $\mathrm{HCl}$ ), Int. J. Quantum Chem. 106, 1009-1019 (2006)

30. I. L. Karle, R. J. Butcher, M. A. Wolak, D. A. d. S. Filho, M. Uchida, J.-L. Brédas and Z. H. Kafafi, Cooperative $\mathrm{CH} \cdots \pi$ interactions in the crystal structure of 2,5-di(3-biphenyl)-1,1dimethyl-3,4-diphenyl-silole and Its effect on Its electronic properties, J. Phys. Chem. C 111, 9543 - 9547 (2007)

31. M. Nishio, Y. Umezawa, K. Honda, S. Tsuboyama and H. Suezawa, CH/ $\pi$ hydrogen bonds in organic and organometallic chemistry, CrystEngComm 11, 1757-1788 (2009)

32. K. P. Gierszal, J. G. Davis, M. D. Hands, D. S. Wilcox, L. V. Slipchenko and D. Ben-Amotz, $\pi$-Hydrogen bonding in liquid water, J. Phys. Chem. Lett. 2, 2930-2933 (2011)

33. S. Kumar, V. Pande and A. Das, $\pi$-Hydrogen bonding wins over conventional hydrogen bonding interaction: A jet-cooled study of indole -.. furan heterodimer, J. Phys. Chem. A 116, 1368-1374 (2012)

34. P. Mastrorilli, V. Gallo, S. Todisco, M. Latronico and G. Saielli, Uncovering Intramolecular $\pi$ Type Hydrogen Bonds in Solution by NMR Spectroscopy and DFT Calculations, Chem. Eur. J. 22, 7964-7969 (2016)

35. A. E. Aliev, J. R. T. Arendorf, I. Pavlakos, R. B. Moreno, M. J. Porter, H. S. Rzepa and W. B. Motherwell, Surfing $\pi$ Clouds for Noncovalent Interactions: Arenes versus Alkenes, Angew. Chem. Int. Ed. 54, 551-555 (2015)

36. S. J. Grabowski, W. A. Sokalski and J. Leszczynski, Can H... $\sigma, \pi \ldots H+\ldots \sigma$ and $\sigma \ldots \mathrm{H}+\ldots \sigma$ interactions be classified as H-bonded?, Chem. Phys. Lett. 432, 33-39 (2006) 
37. S. J. Grabowski, A-H... $\sigma$ Hydrogen Bonds: Dihydrogen and Cycloalkanes as Proton Acceptors, ChemPhysChem. 20, 565-574 (2019)

38. I. Alkorta, J. Elguero and J. E. D. Bene, An ab initio investigation of the properties of $\mathrm{H}_{2}: \mathrm{HX}$ hydrogen-bonded complexes, Chem. Phys. Lett. 489, 159-163 (2010)

39. S. J. Grabowski, Dihydrogen bond and X-H $\cdots \sigma$ interaction as sub-classes of hydrogen bond, $J$. Phys. Org. Chem. 26, 452-459 (2013)

40. F. Pirani, D. Cappelletti, L. Belpassi and F. Tarantelli, Intermolecular Interaction in the $\mathrm{NH}_{3}-$ $\mathrm{H}_{2}$ and $\mathrm{H}_{2} \mathrm{O}-\mathrm{H}_{2}$ Complexes by Molecular Beam Scattering Experiments: The Role of Charge Transfer, J. Phys. Chem. A 117, 12601-12607 (2013)

41. E. A. Kvyatkovskaya, E. V. Nikitina, V. N. Khrustalev, B. Galmés, F. I. Zubkov and A. Frontera, Through space " $\alpha$-effect" between the O-bridge atoms in diepoxybenzo[de]isothiochromene derivatives, Eur. J. Org. Chem. (in press) DOI 10.1002/ejoc.201901169

42. Arunan, E.; Desiraju, G. R.; Klein, R. A.; Sadlej, J.; Scheiner, S.; Alkorta, I.; Clary, D. C.; Crabtree, R. H.; Dannenberg, J. J.; Hobza, P.; Kjaergaard, H. G.; Legon, A. C.; Mennucci, B.; Nesbitt, D. J. Definition of the Hydrogen Bond. Pure Appl. Chem. 2011, 83, 1637-1641.

43. G. C. Pimentel and A. L. McClellan. The Hydrogen Bond. Freeman: San Francisco, 1960.

44. S. N. Vinogradov and R. H. Linnell. Hydrogen Bonding. Van Nostrand-Reinhold: New York, 1971.

45. M. D. Joesten and L. J. Schaad. Hydrogen Bonding. Marcel Dekker: New York, 1974; p 622.

46. G. Gilli and P. Gilli. The Nature of the Hydrogen Bond. Oxford University Press: Oxford, UK, 2009; p 313.

47. P. Schuster. Hydrogen Bonds. Springer-Verlag: Berlin, 1984; Vol. 120, p 117.

48. P. Schuster, G. Zundel and C. Sandorfy. The Hydrogen Bond. Recent Developments in Theory and Experiments. North-Holland Publishing Co.: Amsterdam, 1976.

49. S. J. Grabowski. Hydrogen Bonding - New Insights. Springer: Dordrecht, Netherlands, 2006.

50. S. Scheiner. Hydrogen Bonding: A Theoretical Perspective. Oxford University Press: New York, 1997; p 375.

51. A. Weller, Intramolecular proton transfer in excited states, Z. Elektrochem. 60, 1144-1147 (1956)

52. C. A. Taylor, M. A. El-Bayoumi and M. Kasha, Excited-state two-proton tautomerism in hydrogen-bonded N-heterocyclic base pairs, Proc. Nat. Acad. Sci., USA 63, 253-260 (1969)

53. P. K. Sengupta and M. Kasha, Excited-state proton transfer spectroscopy on 3-hyroxyflavone and quercetin, Chem. Phys. Lett. 68, 382-385 (1979)

54. P. T. Chou, D. McMorrow, T. J. Aartsma and M. Kasha, The proton-transfer laser. Gain spectrum and amplification of spontaneous emission of 3-hydroxyflavone, J. Phys. Chem. 88, 4596-4599 (1984)

55. T. Nishiya, S. Yamauchi, N. Hirota, M. Baba and I. Hanazaki, Fluorescence studies of the intramolecularly hydrogen-bonded molecules o-hydroxyacetophenone and salicylamide and related molecules, J. Phys. Chem. 90, 5730-5735 (1986)

56. S. Nagaoka, M. Fujita, T. Takemura and H. Baba, Fluorescence from an upper excited state of o-hydroxybenzaldehyde in the vapor phase, Chem. Phys. Lett. 123, 123-125 (1986)

57. N. P. Ernsting and B. Nikolaus, Dye-laser pulse shortening by transient absorption following excited-state intramolecular proton transfer, Appl. Phys. B. 39, 155-164 (1986)

58. M. L. Martinez, W. C. Cooper and P.-T. Chou, A novel excited-state intramolecular proton transfer molecule, 10-hydroxybenzo[h]quinoline, Chem. Phys. Lett. 193, 151-154 (1992)

59. T. Werner, Triplet deactivation in benzotriazole-type ultraviolet stabilizers, J. Phys. Chem. 83, 320-329 (1979) 
60. R. M. Tarkka, X. Zhang and S. A. Jenekhe, Electrically generated intramolecular proton transfer: Electroluminescence and stimulated emission from polymers, J. Am. Chem. Soc. 118, 9438-9439 (1996)

61. D. L. Williams and J. Heller, Intramolecular proton transfer reactions in excited fluorescent compounds, J. Phys. Chem. 74, 4473-4480 (1970)

62. H. J. Heller and H. R. Blattmann, Some aspects of stabilization of polymers against light, Pure Appl. Chem. 36, 141-161 (1973)

63. Z. Latajka and S. Scheiner, Proton transfer in the ground and first excited triplet states of malonaldehyde, J. Phys. Chem. 96, 9764-9767 (1992)

64. K. Luth and S. Scheiner, Excited-state energetics and proton-transfer barriers in malonaldehyde, J. Phys. Chem. 98, 3582-3587 (1994)

65. Y. Yang, D. Li, C. Li, Y. Liu and K. Jiang, Asymmetric substitution changes the UV-induced nonradiative decay pathway and the spectra behaviors of $\beta$-diketones, Spectrochimica Acta Part A: Molecular and Biomolecular Spectroscopy 207, 209-215 (2019)

66. T. Tsutsumi, Y. Ono, Z. Arai and T. Taketsugu, Visualization of the Intrinsic Reaction Coordinate and Global Reaction Route Map by Classical Multidimensional Scaling, J. Chem. Theory Comput. 14, 4263-4270 (2018)

67. J. Zamastil and D. Šimsa, Quantum effects and quantum chaos in multidimensional tunneling, Physical Review E 96, 062201 (2017)

68. K. R. Nandipati, A. K. Kanakati, H. Singh and S. Mahapatra, Controlled intramolecular Htransfer in malonaldehyde in the electronic ground state mediated through the conical intersection of $1 n \pi *$ and $1 \pi \pi^{*}$ excited electronic states, Phys. Chem. Chem. Phys. 21, 2001820030 (2019)

69. J. D. Coe and T. J. Martínez, Ab Initio Molecular Dynamics of Excited-State Intramolecular Proton Transfer around a Three-State Conical Intersection in Malonaldehyde, J. Phys. Chem. A 110, 618-630 (2006)

70. A. L. Sobolewski and W. Domcke, Photophysics of malonaldehyde: An ab initio study, $J$. Phys. Chem. A 103, 4494-4504 (1999)

71. K. Luth and S. Scheiner, Proton transfer in ground and excited electronic states of glyoxalmonohydrazine, J. Phys. Chem. 99, 7352-7359 (1995)

72. X. Duan and S. Scheiner, Ground and excited state intramolecular proton transfer in OCCNN ring, Chem. Phys. Lett. 204, 36-44 (1993)

73. M. C. Rovira and S. Scheiner, Transfer of a proton between $\mathrm{N}$ atoms in excited electronic states of 1,5-diaza-1,3-pentadiene, J. Phys. Chem. 99, 9854-9861 (1995)

74. S. Scheiner, T. Kar and M. Cuma, Excited state intramolecular proton transfer in anionic analogues of malonaldehyde, J. Phys. Chem. A 101, 5901-5909 (1997)

75. M. V. Vener and S. Scheiner, Hydrogen bonding and proton transfer in the ground and lowest excited singlet states of o-hydroxyacetophenone, J. Phys. Chem. 99, 642-649 (1995)

76. M. Cuma, S. Scheiner and T. Kar, Effect of adjoining aromatic ring upon excited state proton transfer. o-Hydroxybenzaldehyde, J. Mol. Struct. (Theochem) 467, 37-49 (1999)

77. M. V. Vener, S. Scheiner and N. D. Sokolov, Theoretical study of hydrogen bonding and proton transfer in the ground and lowest excited singlet states of tropolone, J. Chem. Phys. 101, 9755-9765 (1994)

78. M. Forés and S. Scheiner, Effects of chemical substitution upon excited state proton transfer. Fluoroderivatives of salicylaldimine, Chem. Phys. 246, 65-74 (1999)

79. M. Yi and S. Scheiner, Proton transfer between phenol and ammonia in ground and excited electronic states, Chem. Phys. Lett. 262, 567-572 (1996) 
80. S. Scheiner, Theoretical studies of excited state proton transfer in small model systems, $J$. Phys. Chem. A 104, 5898-5909 (2000)

81. X. Pang, C. Jiang, W. Xie and W. Domcke, Photoinduced electron-driven proton transfer from water to an N-heterocyclic chromophore: nonadiabatic dynamics studies for pyridine-water clusters, Phys. Chem. Chem. Phys. 21, 14073-14079 (2019)

82. X. Pang, J. Ehrmaier, X. Wu, C. Jiang, W. Xie, A. L. Sobolewski and W. Domcke, Photoinduced hydrogen-transfer reactions in pyridine-water clusters: Insights from excitedstate electronic-structure calculations, Chem. Phys. 515, 550-556 (2018)

83. X. Wu, T. N. V. Karsili and W. Domcke, Role of Electron-Driven Proton-Transfer Processes in the Ultrafast Deactivation of Photoexcited Anionic 8-oxoGuanine-Adenine and 8oxoGuanine-Cytosine Base Pairs, Molecules 22, 135 (2017)

84. N. T. Trung, P. N. Khanh, A. J. P. Carvalho and M. T. Nguyen, Remarkable shifts of Csp2-H and $\mathrm{O}-\mathrm{H}$ stretching frequencies and stability of complexes of formic acid with formaldehydes and thioformaldehydes, J. Comput. Chem. 40, 1387-1400 (2019)

85. A. L. Bednowitz and B. Post, Direct determination of the crystal structure of $\beta$-fumaric acid, Acta Cryst. 21, 566-571 (1966)

86. S. Glasstone, The structure of some molecular complexes in the liquid phase, Trans. Faraday Soc. 33, 200-214 (1937)

87. J. F. J. Dippy, The dissociation constants of monocarboxylic acids; Their measurement and their significance in theoretical organic chemistry, Chem. Rev. 25, 151-211 (1939)

88. D. J. Sutor, The C-H*OO hydrogen bond in crystals, Nature 195, 68-69 (1962)

89. A. Karpfen, On the interaction of propynal with $\mathrm{HNO}, \mathrm{HF}, \mathrm{HCl}, \mathrm{H} 2 \mathrm{O}, \mathrm{CH} 3 \mathrm{OH}$, and NH3: Red- and blue-shifting hydrogen bonds and tetrel bonds, Comput. Theor. Chem. 1160, 1-13 (2019)

90. B. Behera and P. K. Das, Blue-Shifted Hydrogen Bonding in the Gas Phase CH/D3CN …HCCl3 Complexes, J. Phys. Chem. A 123, 1830-1839 (2019)

91. L. Zhang and D. Li, An insight into intramolecular blue-shifting $\mathrm{CH} \cdots \pi$ hydrogen bonds in 1,3-hexadien-5-yne and its halogen-substituted derivatives, Chem. Phys. 518, 58-68 (2019)

92. S. Scheiner. CH..O Hydrogen Bonding. In Advances in Molecular Structure Research, Hargittai, M.; Hargittai, I., Eds. JAI Press: Stamford, CT, 2000; Vol. 6, pp 159-207.

93. A. Masunov, J. J. Dannenberg and R. H. Contreras, C-H bond-shortening upon hydrogen bond formation: Influence of an electric field, J. Phys. Chem. A 105, 4737-4740 (2001)

94. L. Pejov and K. Hermansson, On the nature of blueshifting hydrogen bonds: Ab initio and density functional studies of several fluoroform complexes, J. Chem. Phys. 119, 313-324 (2003)

95. W. Qian and S. Krimm, Vibrational spectroscopy of hydrogen bonding: Origin of the different behavior of the C-H‥O hydrogen bond, J. Phys. Chem. A 106, 6628-6636 (2002)

96. X. Li, L. Liu and H. B. Schlegel, On the physical origin of blue-shifted hydrogen bonds, J. Am. Chem. Soc. 124, 9639-9647 (2002)

97. I. V. Alabugin, M. Manoharan, S. Peabody and F. Weinhold, Electronic basis of improper hydrogen bonding: A subtle balance of hyperconjugation and rehybridization, J. Am. Chem. Soc. 125, 5973-5987 (2003)

98. J. Joseph and E. D. Jemmis, Red-, blue-, or no-shift hydrogen bonds: A unified explanation, $J$. Am. Chem. Soc. 129, 4620-4632 (2007)

99. A. Karpfen and E. S. Kryachko, On the intramolecular origin of the blue shift of A-H stretching frequencies: Triatomic hydrides HAX, J. Phys. Chem. A 113, 5217-5223 (2009)

100. S. J. Grabowski, Red- and blue-shifted hydrogen bonds: The Bent rule from quantum theory of atoms in molecules perspective, J. Phys. Chem. A 115, 12789-12799 (2011) 
101. Y. Mo, C. Wang, L. Guan, B. Braïda, P. C. Hiberty and W. Wu, On the Nature of Blueshifting Hydrogen Bonds, Chem. Eur. J. 20, 8444-8452 (2014)

102. Y. Gu, T. Kar and S. Scheiner, Fundamental properties of the $\mathrm{CH} \cdots \mathrm{O}$ interaction: Is it a true hydrogen bond?, J. Am. Chem. Soc. 121, 9411-9422 (1999)

103. S. Scheiner, Y. Gu and T. Kar, Evaluation of the H-bonding properties of $\mathrm{CH} \cdots \mathrm{O}$ interactions based upon NMR spectra, J. Mol. Struct. (Theochem) 500, 441-452 (2000)

104. S. Scheiner, S. J. Grabowski and T. Kar, Influence of hybridization and substitution upon the properties of the CH.O hydrogen bond, J. Phys. Chem. A 105, 10607-10612 (2001)

105. S. Scheiner and T. Kar, Red versus blue-shifting hydrogen bonds: Are there fundamental distinctions?, J. Phys. Chem. A 106, 1784-1789 (2002)

106. Y. Gu, T. Kar and S. Scheiner, Comparison of the $\mathrm{CH} \cdots \mathrm{N}$ and $\mathrm{CH} \cdots \mathrm{O}$ interactions involving substituted alkanes, J. Mol. Struct. 552, 17-31 (2000)

107. S. Scheiner, T. Kar and Y. Gu, Strength of the $\mathrm{C}^{\alpha} \mathrm{H} \cdot \mathrm{O}$ hydrogen bond of amino acid residues, J. Biol. Chem. 276, 9832-9837 (2001)

108. S. Scheiner, T. Kar and J. Pattanayak, Comparison of various types of hydrogen bonds involving aromatic amino acids, J. Am. Chem. Soc. 124, 13257-13264 (2002)

109. S. Scheiner, Contributions of $\mathrm{NH} \cdot \mathrm{O}$ and $\mathrm{CH} \cdot \mathrm{O}$ H-bonds to the stability of $\beta$-sheets in proteins, J. Phys. Chem. B 110, 18670-18679 (2006)

110. G. Pohl, J. A. Plumley and J. J. Dannenberg, The interactions of phenylalanines in $\beta$-sheet-like structures from molecular orbital calculations using density functional theory (DFT), MP2, and CCSD(T) methods, J. Chem. Phys. 138, 245102 (2013)

111. C.-S. Wang and C.-L. Sun, Investigation on the individual contributions of N-H $\cdots \mathrm{O}=\mathrm{C}$ and C$\mathrm{H} \cdots \mathrm{O}=\mathrm{C}$ interactions to the binding energies of $\beta$-sheet models, J. Comput. Chem. 31, 1036$1044(2010)$

112. H. Guo, A. Gorin and H. Guo, A peptide-linkage deletion procedure for estimate of energetic contributions of individual peptide groups in a complex environment: Application to parallel $\beta$-sheets, Interdiscip. Sci. Comput. Life Sci. 1, 12-20 (2009)

113. M. V. Vener, A. N. Egorova, D. P. Fomin and V. G. Tsirel'son, A quantum-topological analysis of noncovalent interactions in secondary polyalanine structures, Russ. J. Phys. Chem. B. 3, 541-547 (2009)

114. M. V. Vener, A. N. Egorova, D. P. Fomin and V. G. Tsirelson, QTAIM study of the closedshell interactions in peptide secondary structures: A cluster treatment of oligo- and polyalanines, Chem. Phys. Lett. 440, 279-285 (2007)

115. R. Parthasarathi, S. S. Raman, V. Subramanian and T. Ramasami, Bader's electron density analysis of hydrogen bonding in secondary structural elements of proteins, J. Phys. Chem. A 111, 7141-7148 (2007)

116. S. Scheiner, The strength with which a peptide group can form a hydrogen bond varies with the internal conformation of the polypeptide chain, J. Phys. Chem. B 111, 11312-11317 (2007)

117. S. Scheiner and T. Kar, Effect of solvent upon $\mathrm{CH} \cdot \mathrm{O}$ hydrogen bonds with implications for protein folding, J. Phys. Chem. B 109, 3681-3689 (2005)

118. S. Scheiner, Analysis of catalytic mechanism of serine proteases. Viability of ring-flip hypothesis, J. Phys. Chem. B 112, 6837-6846 (2008)

119. S. Horowitz, U. Adhikari, L. M. A. Dirk, P. A. Del Rizzo, R. A. Mehl, R. L. Houtz, H. M. AlHashimi, S. Scheiner and R. C. Trievel, Manipulating Unconventional CH-Based Hydrogen Bonding in a Methyltransferase via Noncanonical Amino Acid Mutagenesis, ACS Chem. Biol. 9, 1692-1697 (2014) 


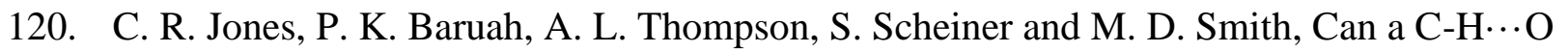
interaction be a determinant of conformation, J. Am. Chem. Soc. 134, 12064-12071 (2012)

121. S. Scheiner, Dissection of the Factors Affecting Formation of a $\mathrm{CH} \cdots \mathrm{O} \mathrm{H}-\mathrm{Bond}$. A Case Study, Cryst. 5, 327 (2015)

122. R. W. Driver, T. D. W. Claridge, S. Scheiner and M. D. Smith, Torsional and Electronic Factors Control the C-H‥O Interaction, Chem. Eur. J. 22, 16513-16521 (2016)

123. U. Adhikari and S. Scheiner, The Magnitude and Mechanism of Charge Enhancement of CH..O H-bonds, J. Phys. Chem. A 117, 10551-10562 (2013)

124. B. Nepal and S. Scheiner, Anionic $\mathrm{CH}^{\cdots} \mathrm{X}^{-}$Hydrogen Bonds: Origin of Their Strength, Geometry, and Other Properties, Chem. Eur. J. 21, 1474-1481 (2015)

125. B. Nepal and S. Scheiner, Microsolvation of Anions by Molecules Forming $\mathrm{CH}^{*} \cdot \mathrm{X}^{-} \mathrm{Hydrogen}$ Bonds, Chem. Phys. 463, 137-144 (2015)

126. S. Scheiner and T. Kar, Spectroscopic and structural signature of the $\mathrm{CH}--\mathrm{O} \mathrm{H}-$ bond, J. Phys. Chem. A 112, 11854-11860 (2008)

127. S. Scheiner, Identification of spectroscopic patterns of $\mathrm{CH}--\mathrm{O} \mathrm{H}-$ bonds in dipeptides, J. Phys. Chem. B 113, 10421-10427 (2009)

128. S. Scheiner, Effect of $\mathrm{CH}$...O hydrogen bond length on the geometric and spectroscopic features of the peptide unit of proteins, Int. J. Quantum Chem. 110, 2775-2783 (2010)

129. O. Hassel, Structural aspects of interatomic charge-transfer bonding, Science 170, 497-502 (1970)

130. J. P. M. Lommerse, A. J. Stone, R. Taylor and F. H. Allen, The nature and geometry of intermolecular interactions between halogens and oxygen or nitrogen, J. Am. Chem. Soc. 118, 3108-3116 (1996)

131. F. H. Allen, J. P. M. Lommerse, V. J. Hoy, J. A. K. Howard and G. R. Desiraju, Halogen $\cdots \mathrm{O}$ (nitro) supramolecular synthon in crystal engineering: A combined crystallographic database and ab initio molecular orbital study, Acta Cryst. B53, 1006-1016 (1997)

132. S. Ikuta, Anisotropy of electron-density distribution around atoms in molecules: N, P, O and S atoms, J. Mol. Struct. (Theochem) 205, 191-201 (1990)

133. V. R. Hathwar and T. N. G. Row, Nature of $\mathrm{Cl} \cdots \mathrm{Cl}$ intermolecular interactions via experimental and theoretical charge density analysis: Correlation of polar flattening effects with geometry, J. Phys. Chem. A 114, 13434-13441 (2010)

134. R. Sedlak, M. H. Kolář and P. Hobza, Polar Flattening and the Strength of Halogen Bonding, J. Chem. Theory Comput. 11, 4727-4732 (2015)

135. P. Politzer, P. Lane, M. C. Concha, Y. Ma and J. S. Murray, An overview of halogen bonding, J. Mol. Model. 13, 305-311 (2007)

136. T. Clark, M. Hennemann, J. S. Murray and P. Politzer, Halogen bonding: the $\sigma$-hole, J. Mol. Model. 13, 291-296 (2007)

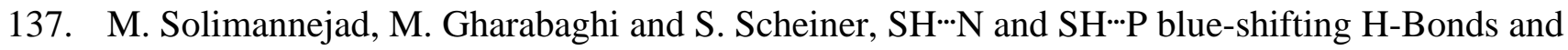
N...P interactions in complexes pairing HSN with amines and phosphines, J. Chem. Phys. 134, $024312(2011)$

138. S. Scheiner, A new noncovalent force: Comparison of P*-N Interaction with hydrogen and halogen bonds, J. Chem. Phys. 134, 094315 (2011)

139. S. Scheiner, Effects of multiple substitution upon the P*NN noncovalent interaction, Chem. Phys. 387, 79-84 (2011)

140. S. Scheiner, Effects of substituents upon the P*-N noncovalent interaction: The limits of its strength, J. Phys. Chem. A 115, 11202-11209 (2011)

141. S. Scheiner, Can two trivalent $\mathrm{N}$ atoms engage in a direct $\mathrm{N} \cdots \mathrm{N}$ noncovalent interaction?, Chem. Phys. Lett. 514, 32-35 (2011) 
142. S. Scheiner, The pnicogen bond: Its relation to hydrogen, halogen, and other noncovalent bonds, Acc. Chem. Res. 46, 280-288 (2013)

143. S. Scheiner, Detailed comparison of the pnicogen bond with chalcogen, halogen and hydrogen bonds, Int. J. Quantum Chem. 113, 1609-1620 (2013)

144. S. Scheiner, On the properties of $X \cdots \times N$ noncovalent interactions for first-, second- and thirdrow X atoms, J. Chem. Phys. 134, 164313 (2011)

145. U. Adhikari and S. Scheiner, Effects of Charge and Substituent on the $\mathrm{S} \cdots \mathrm{N}$ Chalcogen Bond, J. Phys. Chem. A 118, 3183-3192 (2014)

146. V. d. P. N. Nziko and S. Scheiner, Chalcogen Bonding between Tetravalent SF 4 and Amines, J. Phys. Chem. A 118, 10849-10856 (2014)

147. L. M. Azofra, I. Alkorta and S. Scheiner, Chalcogen Bonds in Complexes of SOXY (X, Y = F, Cl) with Nitrogen Bases, J. Phys. Chem. A 119, 535-541 (2015)

148. V. d. P. N. Nziko and S. Scheiner, Intramolecular S...O Chalcogen Bond as Stabilizing Factor in Geometry of Substituted Phenyl-SF 3 Molecules, J. Org. Chem. 80, 2356-2363 (2015)

149. V. d. P. N. Nziko and S. Scheiner, $\mathrm{S} \cdots \pi$ Chalcogen Bonds between $\mathrm{SF}_{2}$ or $\mathrm{SF}_{4}$ and C-C Multiple Bonds, J. Phys. Chem. A 119, 5889-5897 (2015)

150. R. E. Rosenfield, R. Parthasarathy and J. D. Dunitz, Directional preferences of nonbonded atomic contacts with divalent sulfur. 1. Electrophiles and nucleophiles, J. Am. Chem. Soc. 99, 4860-4862 (1977)

151. F. T. Burling and B. M. Goldstein, Computational studies of nonbonded sulfur-oxygen and selenium-oxygen interactions in the thiazole and selenazole nucleosides, J. Am. Chem. Soc. 114, 2313-2320 (1992)

152. M. Iwaoka and S. Tomoda, A Model Study on the Effect of an Amino Group on the Antioxidant Activity of Glutathione Peroxidase, J. Am. Chem. Soc. 116, 2557-2561 (1994)

153. J. E. Del Bene, I. Alkorta and J. Elguero, Probing C $\cdots$ S chalcogen bonds in complexes SC:SHX, for X = NO2, NC, F, Cl, CN, CCH, and NH2, Chem. Phys. Lett. 721, 86-90 (2019)

154. M. D. Esrafili, P. Mousavian and F. Mohammadian-Sabet, The influence of hydrogen- and lithium-bonding on the cooperativity of chalcogen bonds: A comparative ab initio study AU Esrafili, Mehdi D, Mol. Phys. 117, 726-733 (2019)

155. I. Alkorta and A. Legon, An Ab Initio Investigation of the Geometries and Binding Strengths of Tetrel-, Pnictogen-, and Chalcogen-Bonded Complexes of $\mathrm{CO}_{2}, \mathrm{~N}_{2} \mathrm{O}$, and $\mathrm{CS}_{2}$ with Simple Lewis Bases: Some Generalizations, Molecules 23, 2250 (2018)

156. R. Gleiter, G. Haberhauer, D. B. Werz, F. Rominger and C. Bleiholder, From Noncovalent Chalcogen-Chalcogen Interactions to Supramolecular Aggregates: Experiments and Calculations, Chem. Rev. 118, 2010-2041 (2018)

157. S. Scheiner, Comparison of $\mathrm{CH} \cdots \mathrm{O}, \mathrm{SH} \cdots \mathrm{O}$, Chalcogen, and Tetrel Bonds Formed by Neutral and Cationic Sulfur-Containing Compounds, J. Phys. Chem. A 119, 9189-9199 (2015)

158. V.d. P. N. Nziko and S. Scheiner, Comparison of $\pi$-hole tetrel bonding with $\sigma$-hole halogen bonds in complexes of $\mathrm{XCN}(\mathrm{X}=\mathrm{F}, \mathrm{Cl}, \mathrm{Br}, \mathrm{I})$ and $\mathrm{NH}_{3}$, Phys. Chem. Chem. Phys. 18, 35813590 (2016)

159. M. Liu, Q. Li and S. Scheiner, Comparison of tetrel bonds in neutral and protonated complexes of pyridine $\mathrm{TF}_{3}$ and furan $\mathrm{TF}_{3}(\mathrm{~T}=\mathrm{C}, \mathrm{Si}$, and $\mathrm{Ge})$ with $\mathrm{NH}_{3}$, Phys. Chem. Chem. Phys. 19, 5550-5559 (2017)

160. S. Scheiner, Systematic Elucidation of Factors That Influence the Strength of Tetrel Bonds, $J$. Phys. Chem. A 121, 5561-5568 (2017)

161. S. Scheiner, Steric Crowding in Tetrel Bonds, J. Phys. Chem. A 122, 2550-2562 (2018)

162. W. Zierkiewicz, M. Michalczyk and S. Scheiner, Implications of monomer deformation for tetrel and pnicogen bonds, Phys. Chem. Chem. Phys. 20, 8832-8841 (2018) 
163. W. Zierkiewicz, M. Michalczyk, R. Wysokiński and S. Scheiner, Dual Geometry Schemes in Tetrel Bonds: Complexes between $\mathrm{TF}_{4}(\mathrm{~T}=\mathrm{Si}, \mathrm{Ge}, \mathrm{Sn})$ and Pyridine Derivatives, Molecules 24, 376 (2019)

164. R. C. Trievel and S. Scheiner, Crystallographic and Computational Characterization of Methyl Tetrel Bonding in S-Adenosylmethionine-Dependent Methyltransferases, Molecules 23, 29652981 (2018)

165. S. Scheiner, Ability of IR and NMR Spectral Data to Distinguish between a Tetrel Bond and a Hydrogen Bond, J. Phys. Chem. A 122, $7852-7862$ (2018)

166. S. Scheiner, Dependence of NMR chemical shifts upon $\mathrm{CH}$ bond lengths of a methyl group involved in a tetrel bond, Chem. Phys. Lett. 714, 61-64 (2019)

167. J. Zhang, Q. Hu, Q. Li, S. Scheiner and S. Liu, Comparison of $\sigma$-hole and $\pi$-hole tetrel bonds in complexes of borazine with $\mathrm{TH}_{3} \mathrm{~F}$ and $\mathrm{F}_{2} \mathrm{TO} / \mathrm{H}_{2} \mathrm{TO}(\mathrm{T}=\mathrm{C}, \mathrm{Si}, \mathrm{Ge})$, Int. J. Quantum Chem. 119, e25910 (2019)

168. W. Zierkiewicz, M. Michalczyk and S. Scheiner, Comparison between Tetrel Bonded Complexes Stabilized by $\sigma$ and $\pi$ Hole Interactions, Molecules 23, 1416 (2018)

169. Y. Wei, Q. Li and S. Scheiner, The $\pi$-Tetrel Bond and its Influence on Hydrogen Bonding and Proton Transfer, ChemPhysChem. 19, 736-743 (2018)

170. S. J. Grabowski, Boron and other Triel Lewis Acid Centers: From Hypovalency to Hypervalency, ChemPhysChem. 15, 2985-2993 (2014)

171. S. J. Grabowski, $\pi$-Hole Bonds: Boron and Aluminum Lewis Acid Centers, ChemPhysChem. 16, 1470-1479 (2015)

172. Z. Chi, W. Dong, Q. Li, X. Yang, S. Scheiner and S. Liu, Carbene triel bonds between $\operatorname{TrR}_{3}$ ( $\mathrm{Tr}=\mathrm{B}, \mathrm{Al})$ and N-heterocyclic carbenes, Int. J. Quantum Chem. 119, e25867 (2019)

173. M. Michalczyk, W. Zierkiewicz and S. Scheiner, Triel-Bonded Complexes between $\operatorname{TrR}_{3}$ ( $\mathrm{Tr}=\mathrm{B}, \mathrm{Al}, \mathrm{Ga} ; \mathrm{R}=\mathrm{H}, \mathrm{F}, \mathrm{Cl}, \mathrm{Br}, \mathrm{CH}_{3}$ ) and Pyrazine, ChemPhysChem. 19, 3122-3133 (2018)

174. A. Mukherjee, A. Sanz-Matias, G. Velpula, D. Waghray, O. Ivasenko, N. Bilbao, Jeremy N. Harvey, K. S. Mali and S. De Feyter, Halogenated building blocks for 2D crystal engineering on solid surfaces: lessons from hydrogen bonding, Chem. Sci. 10, 3881-3891 (2019)

175. C. Xu and C. C. J. Loh, A Multistage Halogen Bond Catalyzed Strain-Release Glycosylation Unravels New Hedgehog Signaling Inhibitors, J. Am. Chem. Soc. 141, 5381-5391 (2019)

176. L. Carreras, J. Benet-Buchholz, A. Franconetti, A. Frontera, P. W. N. M. van Leeuwen and A. Vidal-Ferran, Halogen bonding effects on the outcome of reactions at metal centres, Chem. Commun. 55, 2380-2383 (2019)

177. H. Hijazi, A. Vacher, S. Groni, D. Lorcy, E. Levillain, C. Fave and B. Schöllhorn, Electrochemically driven interfacial halogen bonding on self-assembled monolayers for anion detection, Chem. Commun. 55, 1983-1986 (2019)

178. X. Zhang, J. Ren, S. M. Tan, D. Tan, R. Lee and C.-H. Tan, An enantioconvergent halogenophilic nucleophilic substitution $(\mathrm{S}<\mathrm{sub}>\mathrm{N}</ \mathrm{sub}>2 \mathrm{X}$ ) reaction, Science 363, 400-404 (2019)

179. H. Wang, H. K. Bisoyi, A. M. Urbas, T. J. Bunning and Q. Li, The Halogen Bond: An Emerging Supramolecular Tool in the Design of Functional Mesomorphic Materials, Chem. Eur. J. 25, 1369-1378 (2019)

180. C.-Z. Liu, S. Koppireddi, H. Wang, D.-W. Zhang and Z.-T. Li, Halogen Bonding Directed Supramolecular Quadruple and Double Helices from Hydrogen-Bonded Arylamide Foldamers, Angew. Chem. Int. Ed. 58, 226-230 (2019)

181. C. J. Serpell, N. L. Kilah, P. J. Costa, V. Félix and P. D. Beer, Halogen Bond Anion Templated Assembly of an Imidazolium Pseudorotaxane, Angew. Chem. Int. Ed. 49, 5322-5326 (2010) 
182. A. Caballero, N. G. White and P. D. Beer, A bidentate halogen-bonding bromoimidazoliophane receptor for bromide ion recognition in aqueous media, Angew. Chem., Int. Ed. Engl. 50, 1845-1848 (2011)

183. S. M. Walter, F. Kniep, L. Rout, F. P. Schmidtchen, E. Herdtweck and S. M. Huber, Isothermal Calorimetric Titrations on Charge-Assisted Halogen Bonds: Role of Entropy, Counterions, Solvent, and Temperature, J. Am. Chem. Soc. 134, 8507-8512 (2012)

184. L. C. Gilday, N. G. White and P. D. Beer, Halogen- and hydrogen-bonding triazolefunctionalised porphyrin-based receptors for anion recognition, Dalton Trans. 42, 1576615773 (2013)

185. A. Borissov, I. Marques, J. Y. C. Lim, V. Félix, M. D. Smith and P. D. Beer, Anion Recognition in Water by Charge-Neutral Halogen and Chalcogen Bonding Foldamer Receptors, J. Am. Chem. Soc. 141, 4119-4129 (2019)

186. H. A. Klein and P. D. Beer, Iodide Discrimination by Tetra-Iodotriazole Halogen Bonding Interlocked Hosts, Chem. Eur. J. 25, 3125-3130 (2019)

187. R. Hein, A. Borissov, M. D. Smith, P. D. Beer and J. J. Davis, A halogen-bonding foldamer molecular film for selective reagentless anion sensing in water, Chem. Commun. 55, 48494852 (2019)

188. S. Chakraborty, S. Maji, R. Ghosh, R. Jana, A. Datta and P. Ghosh, Aryl-platform-based tetrapodal 2-iodo-imidazolium as an excellent halogen bond receptor in aqueous medium, Chem. Commun. 55, 1506-1509 (2019)

189. B. Nepal and S. Scheiner, Competitive Halide Binding by Halogen Versus Hydrogen Bonding: Bis-triazole Pyridinium, Chem. Eur. J. 21, 13330-13335 (2015)

190. B. Nepal and S. Scheiner, Substituent Effects on the Binding of Halides by Neutral and Dicationic Bis(triazolium) Receptors, J. Phys. Chem. A 119, 13064-13073 (2015)

191. B. Nepal and S. Scheiner, Building a Better Halide Receptor: Optimum Choice of Spacer, Binding Unit, and Halosubstitution, ChemPhysChem. 17, 836-844 (2016)

192. S. Scheiner, Assembly of Effective Halide Receptors from Components. Comparing Hydrogen, Halogen, and Tetrel Bonds, J. Phys. Chem. A 121, 3606-3615 (2017)

193. S. Scheiner, Comparison of halide receptors based on $\mathrm{H}$, halogen, chalcogen, pnicogen, and tetrel bonds, Faraday Disc. 203, 213-226 (2017)

194. S. Scheiner, Tetrel Bonding as a Vehicle for Strong and Selective Anion Binding, Molecules 23, 1147-1155 (2018)

195. S. Scheiner, Differential Binding of Tetrel-Bonding Bipodal Receptors to Monatomic and Polyatomic Anions, Molecules 24, 227 (2019) 


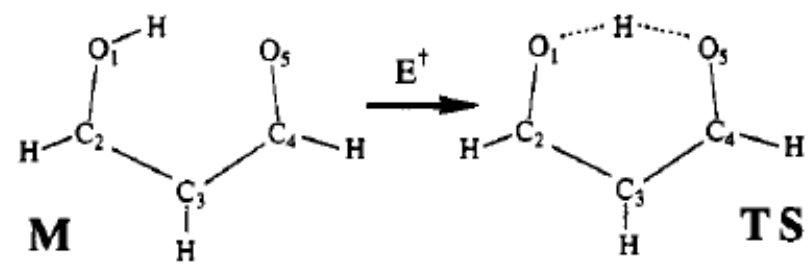

Fig 1. Structure of malonaldehyde (M) and the transition state (TS) for the transfer of the proton between $\mathrm{O}$ atoms.
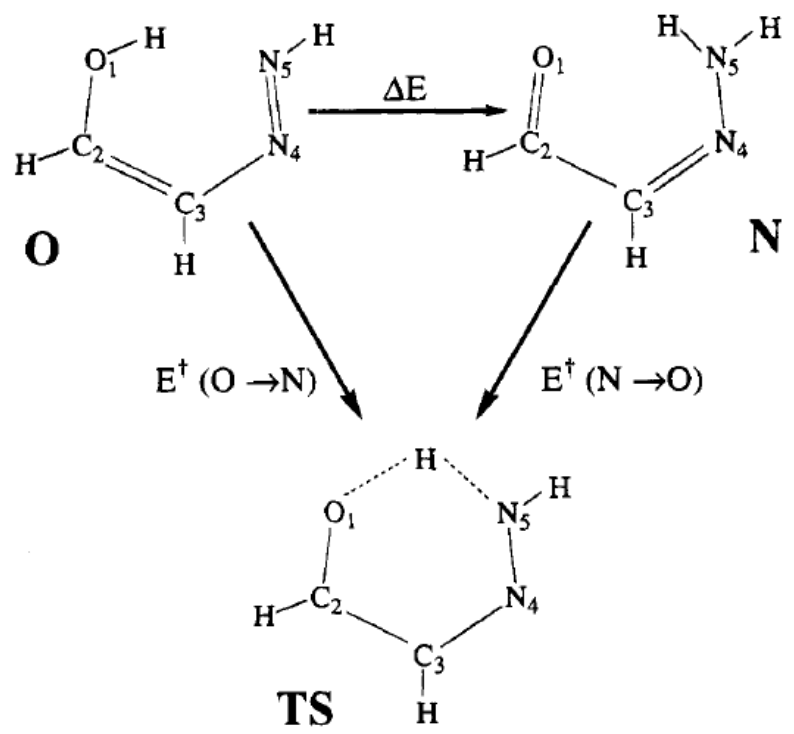

Fig 2. $\mathbf{O}$ and $\mathbf{N}$ tautomers related to asymmetric pT in glyoxalmonohydrazine

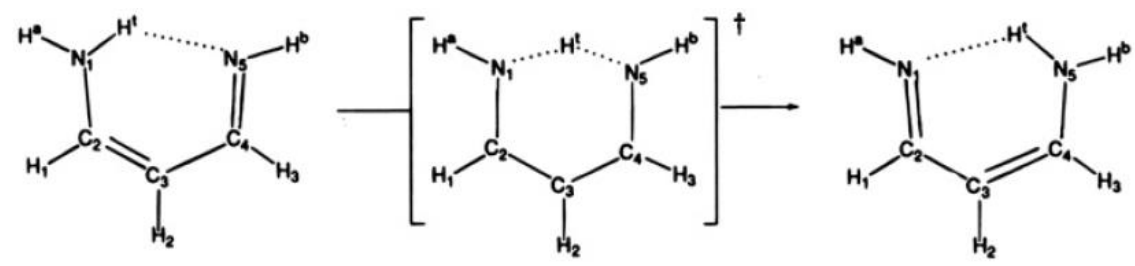

Fig 3. Symmetric proton transfer in 1,5-Diaza-1,3-pentadiene. 


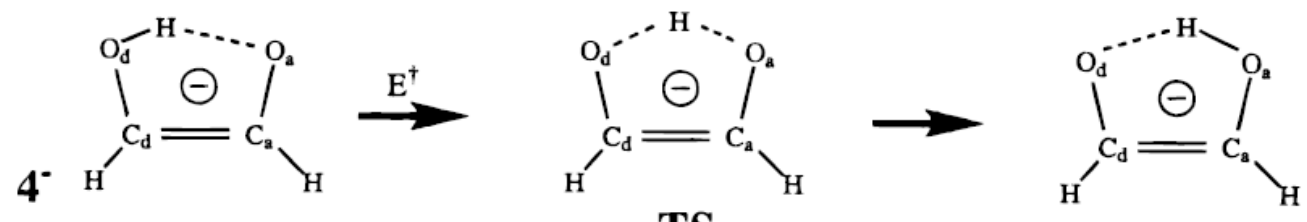

\section{TS}<smiles>CC=Cc1ccc(CCC)cc1</smiles>

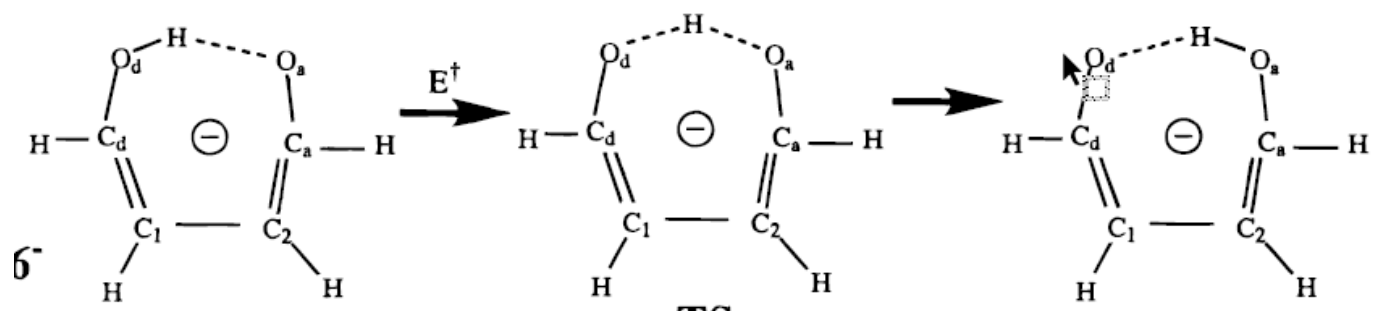

TS

Fig 4. Four (4') and six (6') membered anionic ring analogues of malonaldehyde (5).

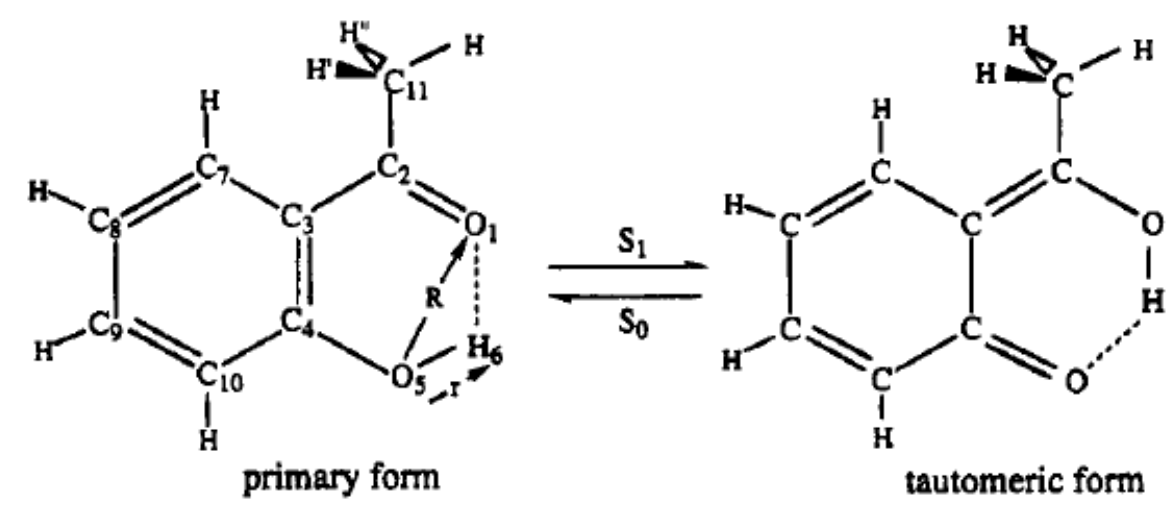

Fig 5. Primary and tautomeric forms of o-hydroxyacetophenone. 


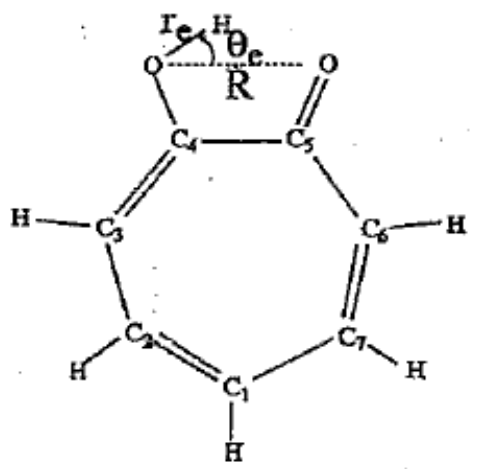

Fig 6. Four-membered OCCO ring attached to 7-membered ring in tropolone system.

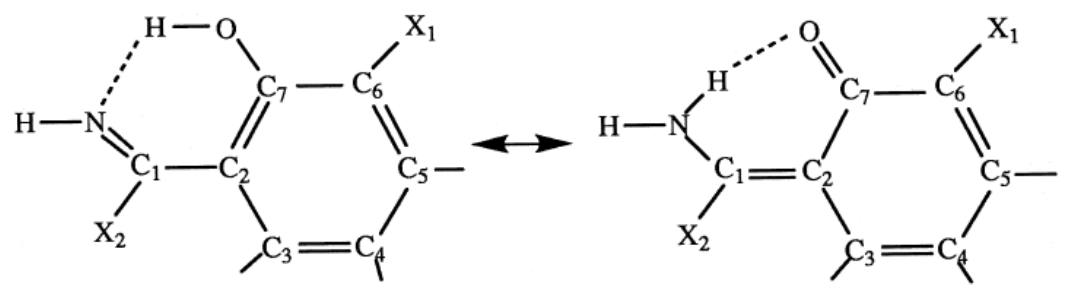

enol

keto

Fig 7. Placement of a F-substituent into salicylaldimine in either $\mathrm{X}_{1}$ or $\mathrm{X}_{2}$ positions.

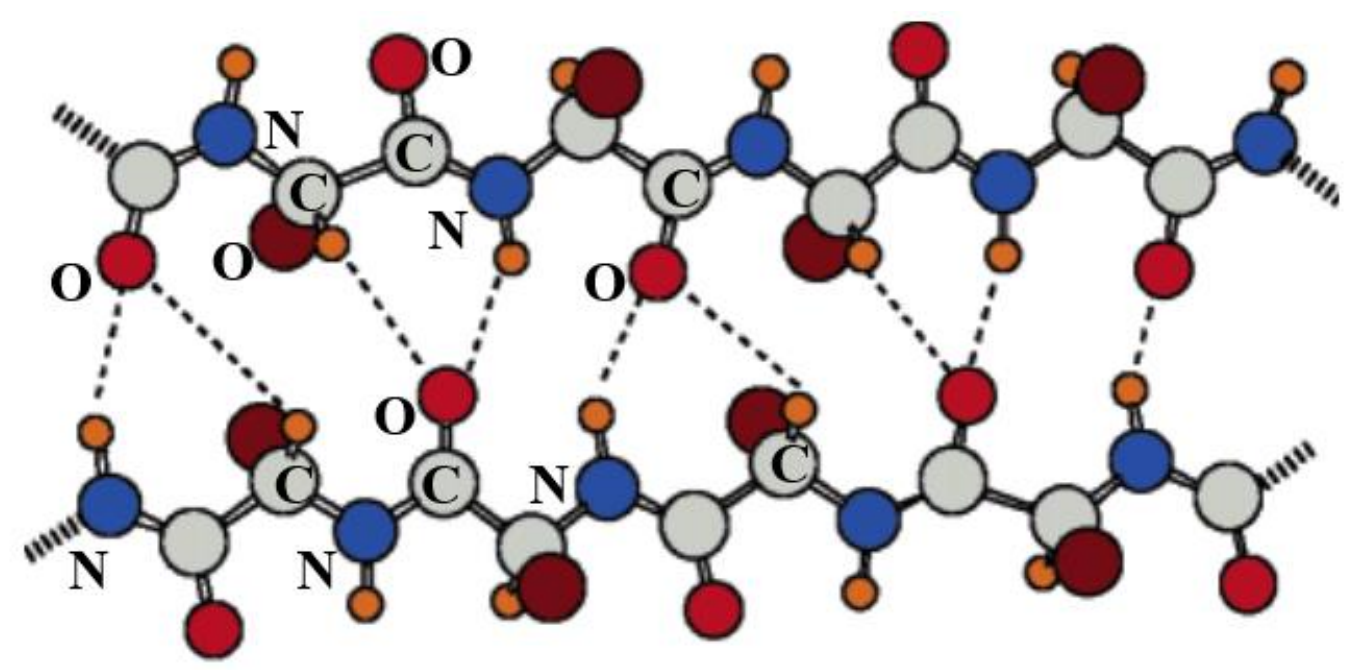

Fig 8. Pair of polypeptide strands in the antiparallel $\beta$-sheet arrangement, indicating putative HBs by broken lines. Brown atoms represent generic $\mathrm{R}$ groups of amino acids. 

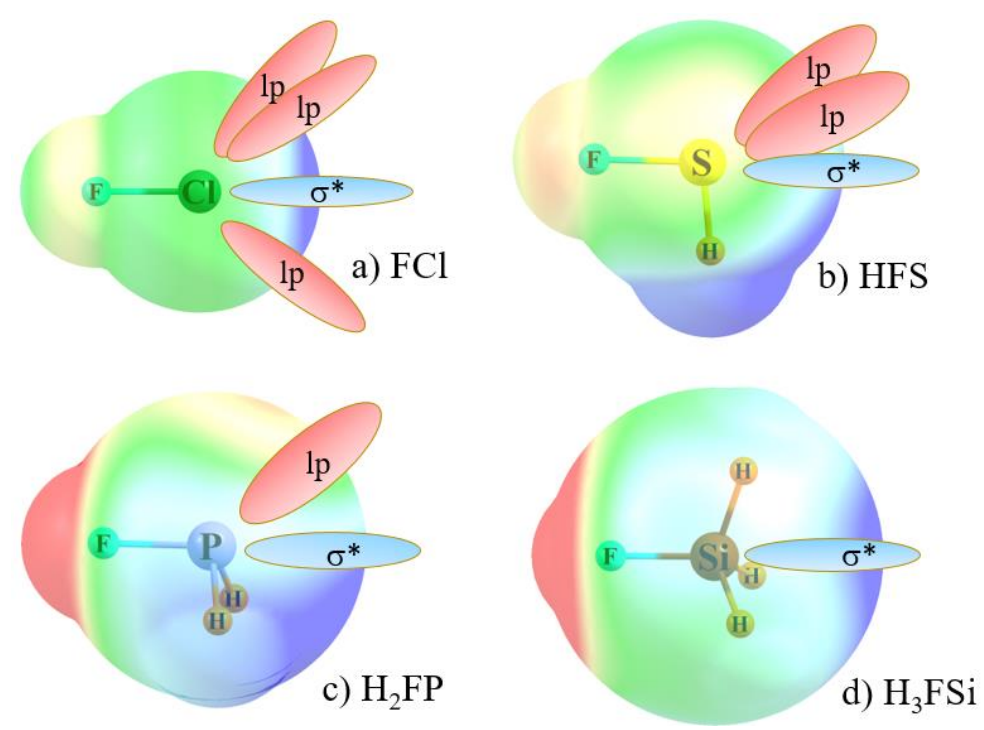

Fig 9. Molecular electrostatic potential surrounding indicated molecules, with blue indicating positive and negative represented by red regions. Light blue oval designates the $\sigma^{*}(\mathrm{~F}-\mathrm{A})$ antibonding orbital that lies directly opposite the F-A covalent bond. Lone pairs on each central A atom are indicated by red ovals.

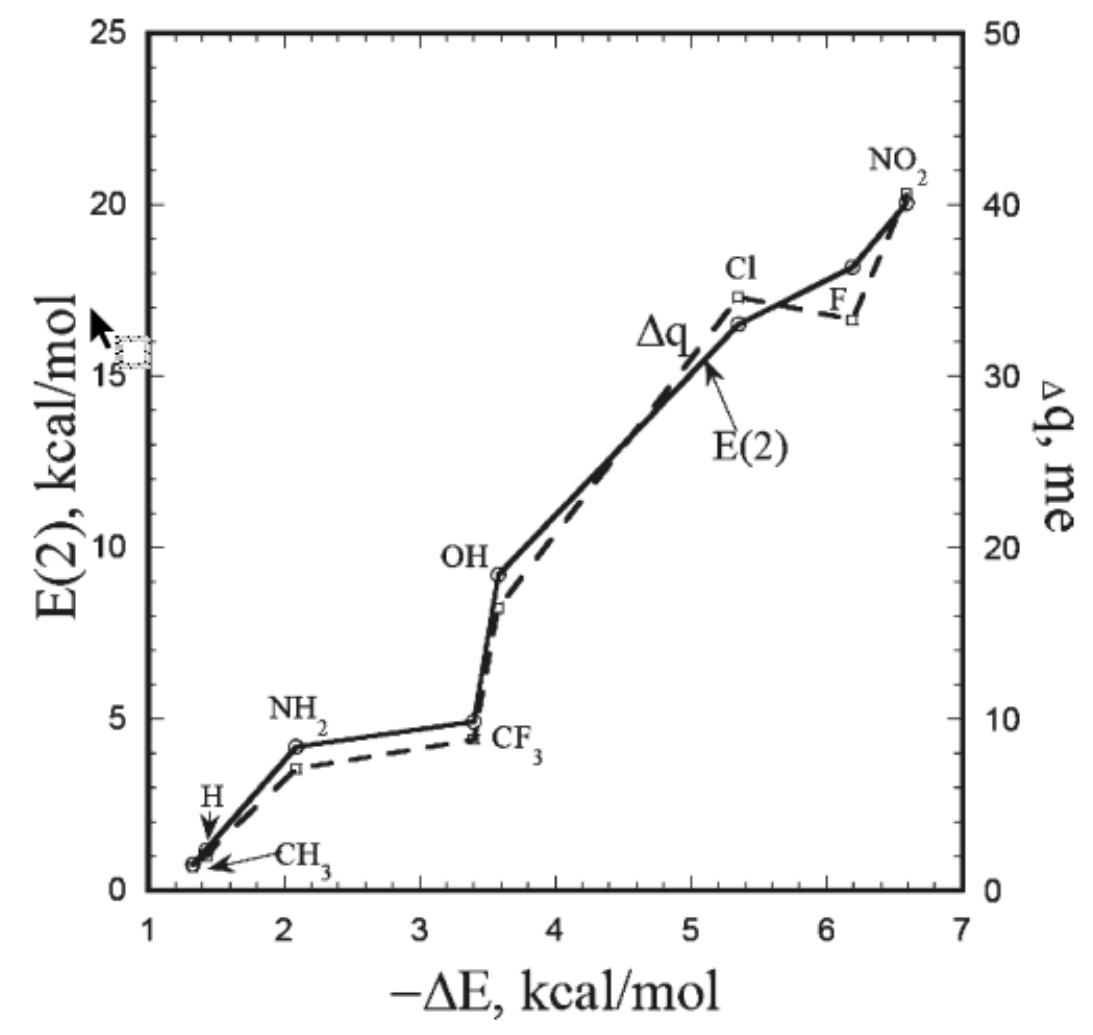

Fig 10. Variation of second-order energy $\mathrm{E}(2)$ and amount of charge transferred from $\mathrm{N}$ lone pair of $\mathrm{NH}_{3}$ to $\sigma^{*}(\mathrm{XP})$ antibonding orbital of $\mathrm{H}_{2} \mathrm{PX}$ as a function of interaction energy $\Delta \mathrm{E}$ 
Steve Scheiner is a professor of computational chemistry at Utah State University. After receiving his PhD from Harvard University in 1976, and proceeding to a Weizmann Postdoctoral Fellowship at Ohio State University, he started his independent academic career at Southern Illinois University, Carbondale. He moved to Utah State University in 2000. His research has centered around various aspects of H-bonds, from their fundamental underpinning to their role in enzymatic activity, from the proton transfers that take place within to their cousins, known as halogen, chalcogen, pnicogen, and tetrel bonds.

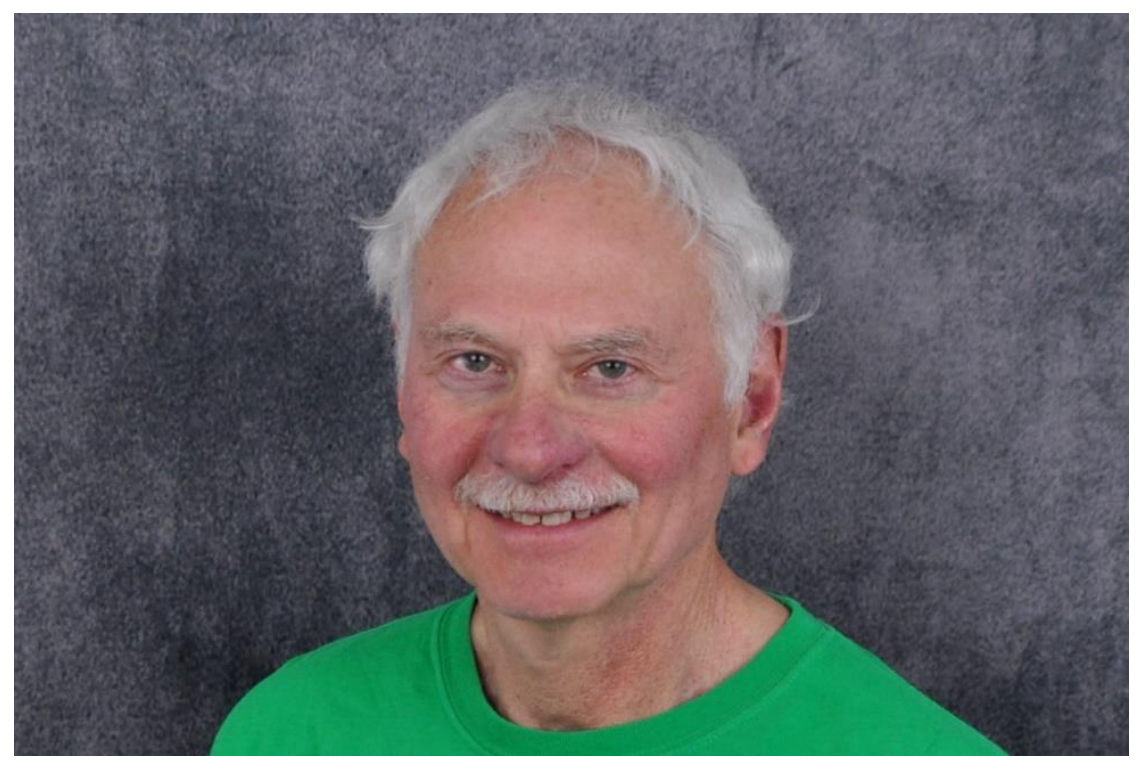

